\title{
Insights and Hopes in Umbilical Cord Blood Stem Cell Transplantations
}

\author{
Somayeh Shahrokhi, ${ }^{1}$ Farid Menaa, ${ }^{2,3}$ Kamran Alimoghaddam, ${ }^{4}$ \\ Colin McGuckin, ${ }^{5}$ and Massoumeh Ebtekar ${ }^{6}$
}

${ }^{1}$ Department of Immunology, School of Medicine, Lorestan University of Medical Sciences, Khorramabad 381351698, Iran
${ }^{2}$ Center of Hematology and Hemotherapy (Hemocentro), School of Medicine and Medical Sciences (FCM),
University of Campinas (UNICAMP), Campinas, 13083-878 Sao Paulo, SP, Brazil
${ }^{3}$ Department of Biomedicine and Biotechnology, Fluorotronics, Inc., San Diego, CA 92081, USA
${ }^{4}$ Hematology Oncology and Stem Cell Transplantation Research Center, Tehran University of Medical Sciences, Tehran 14114, Iran
${ }^{5}$ Cell Therapy Research Institue, 69330 Meyzieu, Lyon, France
${ }^{6}$ Department of Immunology, Faculty of Medical Sciences, Tarbiat Modares University, Tehran 1411713116, Iran

Correspondence should be addressed to Somayeh Shahrokhi, shahrokhi_so@yahoo.com

Received 5 August 2012; Accepted 8 October 2012

Academic Editor: Ali Khraibi

Copyright ( $) 2012$ Somayeh Shahrokhi et al. This is an open access article distributed under the Creative Commons Attribution License, which permits unrestricted use, distribution, and reproduction in any medium, provided the original work is properly cited.

Over 20.000 umblical cord blood transplantations (UCBT) have been carried out around the world. Indeed, UCBT represents an attractive source of donor hematopoietic stem cells (HSCs) and, offer interesting features (e.g., lower graft-versus-host disease) compared to bone marrow transplantation (BMT). Thereby, UCBT often represents the unique curative option against several blood diseases. Recent advances in the field of UCBT, consisted to develop strategies to expand umbilical stem cells and shorter the timing of their engraftment, subsequently enhancing their availability for enhanced efficacy of transplantation into indicated patients with malignant diseases (e.g., leukemia) or non-malignant diseases (e.g., thalassemia major). Several studies showed that the expansion and homing of UCBSCs depends on specific biological factors and cell types (e.g., cytokines, neuropeptides, coculture with stromal cells). In this review, we extensively present the advantages and disadvantages of current hematopoietic stem cell transplantations (HSCTs), compared to UBCT. We further describe the importance of cord blood content and obstetric factors on cord blood selection, and report the recent approaches that can be undertook to improve cord blood stem cell expansion as well as engraftment. Eventually, we provide two majors examples underlining the importance of UCBT as a potential cure for blood diseases.

\section{Introduction}

Umbilical cord blood (UCB) availability as a prospect for therapeutic use was first reported in the British journal, Lancet, in 1939 [1]. The proposed use was transfusional, but outside of the neonatology clinic, the concept was slow to be accepted, with standard adult blood transfusions being more available. Many years passed before E. Donnall Thomas eventually achieved bone marrow transplantation (BMT) in the 1950s, leading to his later Nobel Prize. Along with this clinical milestone, became a slow but growing awareness that UCB might also be of interest, but it was not until the 1970s when the medical brothers Ende published the transplantation of multiple units of UCB into an individual [2]. Sadly, this procedure was not successful, most likely because of the complications related to the multiple immunology disparities of the transplant units. However, the procedure did start a new move to investigate cord blood on a more serious level.

Eventually, in 1988, successful transplant for bone marrow replacement of a sibling with Fanconi's anaemia was achieved and then published in 1989 [3]. The growth of this possibility to use what is one of the largest cellular sources available on the planet, but normally discarded, was 
an exciting move which has now led to UCB being considered an attractive alternative source of donor hematopoietic stem cells (HSCs) in the treatment of both recurrent or refractory malignant hematologic disorders (e.g., leukemia, lymphoma) and nonmalignant blood diseases (e.g., thalassemia, sickle cell disease) [4-6]. Indeed, since its successful initial use in 1988, umbillical cord blood transplantation (UCBT), particularly allogeneic-UCBT, from both related and unrelated donors, is increasingly used worldwide to treat patients, mostly pediatrics, with either malignant or nonmalignant disorders [3, 7-9]. To date, over 20.000 transplantation procedures have been performed from unrelated donor UCB units, and more than 450.000 UCB units have been collected and banked by approximately 50 public cord blood banks worldwide [4, 10-12].

Globally, UBCT presents the following advantages over BMT [4, 11-14]: (i) lower incidence and lower severity of acute and chronic graft-versus-host disease (GVHD), a leading cause of morbidity and mortality; (ii) possibility of extending the number of HLA-antigen mismatches to 1 to 2 of the 6 HLA loci currently considered in UCB transplantation; (iii) lower risk of transmitting latent virus infections (e.g., cytomegalovirus, Epstein-Barr virus, hepatitis viruses, human immunodeficiency virus); (iv) elimination of clinical risk to the donor during hematopoietic stem cell procurement procedures; (v) higher frequency of rare HLA haplotype representation in the donor pool; (vi) a rapid tempo of immune reconstitution. However, these advantages are balanced by two main disadvantages compared to BMT $[4,11-13,15]$ : (i) higher risk of graft rejection because of possible translation of the naive immune system into a blunted allogeneic effect elicited by donor $\mathrm{T}$ lymphocytes (i.e., immunologic barriers to engraftment); (ii) delayed hematopoietic recovery after transplantation, due to a reduced number of hematopoietic progenitor cells that can further contribute to serious infections.

Interestingly, children with nonmalignant disorders experienced a higher rate of graft rejection after UBCT compared with children suffering from a malignant disorder [16-18]. The reason(s) of such difference might be linked to $[8,19-23]$ : (i) the T-cell depletion, (ii) the total nucleated cell (TNC) dose along with the colony-forming unit (CFU) activity and $\mathrm{CD} 34^{+}$cells (HSC) which has a profound impact on engraftment, transplant-related complications (infection risk, survival), (iii) the degree of HLA mismatching (i.e., recipients who had greater than 2 HLA mismatches, assessed by low-resolution HLA typing methods at HLA-A and HLAB loci and by high-resolution at HLA-DRB1, experienced the worst outcomes). The later has a great impact on the incidence and severity of GVHD, engraftment (i.e., neutrophil and platelet count recovery), as well as survival.

Conversely, it was shown that increasing the cell dose of HSC to over $3.5 \times 10^{7} \mathrm{TNC} / \mathrm{kg}$ could partially overcome those negative consequences, especially if the patients experienced previous autologous stem cell transplantations [10, 13]. Nevertheless, in adult recipients, the cell dose constitutes the major limitation which is difficult to overcome if less than two UCB units are used. Indeed, the use of two UCB units, preceded by the application of a reduced intensity preparative regimen, facilitated engraftment and mitigated the difficulties associated with delayed or nonengraftment [24-28].

Eventually, related CBT offers a good probability of success (e.g., possible low occurrence of transplant-related complications and transplant-related mortality (TRM)) as it is mainly associated with a low risk of GVHD [11-14, 29].

\section{Hematopoietic Stem Cell Transplantation from Different Sources: Advantages and Disadvantages}

2.1. Matched Unrelated Versus Umbilical Cord Blood or Haploidentical Transplantation. Hematopoietic stem cell transplantation (HSCT) is a potentially curative option for many cases of hematologic nonmalignant or malignant diseases such as thalassemia major and acute leukemia. Applicability of HSCT is dependent on the presence of suitable hematopoietic stem cell donor. Unfortunately, many patients do not have suitable HLA match donor in family. Therefore, finding an alternative donor is crucial for such cases. The diversity of HLA antigens in community subsequently led to study several alternative sources HSCT such as the use of (i) unrelated donors bone marrow or peripheral blood hematopoietic stem cells, (ii) cord blood stem cells, (iii) finding a donor between extended family (especially in societies with high rate of consanguitniy in marriage), (iv) unrelated mismatch donor, and (v) haploidentical stem cell donor from a family member [30].

Each modality has its own advantages and disadvantages depending on the source of stem cells. Stem cells from live donor is well studied and shows good results when related HLA match donor HSCT is employed [31, 32]. Some advantages are associated with this modality such as (i) potential availability of the donor for further therapeutic maneuvers such as donor lymphocyte infusion (DLI)/boster cell doses or even retransplantation, in case of rejection or relapse, (ii) enough cell doses can be harvested for a successful and safe HSCT, (iii) high chance of finding a suitable donor, especially between white Caucasian race because of more advanced unrelated donor registries and highest number of donors in this population. Nevertheless, those advantages are balanced by some disadvantages such as (i) difficulty of finding a donor between ethnic minorities, (ii) great time consumption (average of 3 months) to find and prepare a donor for HSCT, (iii) unavailability of a potential donor due to personal donor problems, (iv) severe GVHD in case of HLA mismatches, usually greater than 2, (v) high cost of the overall procedure which limit its use in some countries financially limited.

Umbillical cord blood stem cells (UCBSCs) were extensively studied $[3,10,33-36]$ and constitute an acceptable source of cells for permanent engraftment after transplantation. Further, they can elicit graft versus host/leukemia effect. UCBT has also its own advantages and disadvantages. Usually, there is a waste product of pregnancy deliveries, and so, UCBSCs represent valuable sources for preserving lives. The main advantages of this modality are related to 
(i) their easy and immediate availability [37], minimizing donor-related problems, (ii) their low risk of GVHD, thus allowing some acceptable degree of HLA mismatch [10,3335], (iv) their greater expansion and division potential than adult cells that makes the use of one Log cell dose lower than adult cells acceptable for a successful transplantation [38], (v) their nature as immunological naïve cells that might explain lower immunological complications than adult stem cells after UCBT [39-41]. Disadvantages of UCBSCs for transplantation often concern (i) their harvesting limitation that may be lower than the minimum necessary cells dose for a suitable engraftment, especially in adults with larger body mass [10, 33-35], (ii) availability of donors for further therapeutic maneuvers such as DLI and, so, in case of rejection/relapse, fewer therapeutic options remain. One of the major disadvantages of UCBT is the delayed engraftment which predisposes patients to severe infectious complications after transplantation [10,33-35]. Finally, the cost of harvesting and preserving in frozen condition UCBSCs for several years is high and is not favorable for financially poor patients.

Considering the advantages of HSCT, the improvement of transplantation methods, the better knowledge of transplantation immunology, the development of more potent immunosuppressive drugs and antibiotics, the greater experience with mismatch transplantation as well as the possibility of stem cell purification in clinical setting, UCBSCs transplantation rose as a valuable therapeutic option. This option is generally used from family donor with similarity in HLA antigens in one haplotype [42-44]. This is possible by (i) using induction of greater immunosuppression in recipient to prevent from graft rejection and severe GVHD, (ii) purifying HSCs before HSCT and depletion of alloreactive $\mathrm{T}$ cells before transplantation, which can be performed by ex vivo $\mathrm{T}$ cell depletion or in vivo $\mathrm{T}$ cell reduction by $\mathrm{T}$ cell directed monoclonal antibodoies [45] or cyclophosphamide [46], and (iii) using higher cell doses (or even mega cell doses) to prevent rejection of transplanted cells by persistent recipient immunity [44].

Advantages of haploidentical transplantation are obvious. They include (i) universally availability of sibling donors (i.e., parents) for every therapeutic maneuvers (e.g., DLI or retransplant), (ii) short time for finding a suitable donor, (iii) great immunologic reactions against leukemic cells [47], (iv) acceptable cost which is very important for countries with limited financial resources. The disadvantages of haploidentical transplantation include (i) great possibility of rejection, due to preserved recipient immune system or severe GVHD and, (ii) high rate of infectious complications, [48] or posttransplantation secondary malignancies, because of greater and longer immunosupression necessary for prevention of immunological reactions and rejection, (iii) lesser knowledge and experience to manage the eventual complications associated to this procedure.

Although HSCT performed from all of these sources, there are few studies that compare between these modalities. Because of lack of enough evidence for comparison of these modalities, decision making for patients and choosing one of these options remain difficult.

\section{Importance of Cord Blood Content and Obstetric Factors on Cord Blood Selection}

Although UCB is known to have transplant outcome advantages over bone marrow and peripheral blood, one of the known limitations of the use of UCB has been cell number and content $[49,50]$. Variability between UCB units can be analysed in terms of (i) child gender, (ii) obstetric history, (iii) infant birth weight, (iv) gestational stage at parturition, and (v) mother's age at delivery [51]. These factors affect not only choice of cord blood unit for haematological transplantation, but also choice of processing technique. The recommended TNC content for UCB transplantation is a minimum of $2 \times 10^{7} / \mathrm{kg}$ for adults and $3.7 \times 10^{7} / \mathrm{kg}$ for children [52]. Therefore, it is extremely important to determine the best selection processes for donors of UCB to improve quality and applicability of UCB units and in terms of cord blood banking to reduce storage of ineffective blood units (Table 1). UCB cellular subpopulations of interest to transplant can be divided into three distinct groups according to a model previously described [53] from primitive to mature stem cells (Figure 1).

Our work in this area showed that females tend to have an insignificantly higher UCB TNC than males $(P=0.752)$, but a greater concentration of T-cells $\left(\mathrm{CD} 34^{+} / \mathrm{CD}^{+}\right)$than male infants $(P<0.001)$ although a slightly higher trend in early stage HSC $\left(\mathrm{CD} 45^{+} / \mathrm{CD} 34^{-} / \mathrm{CD} 133^{+}, P=0.8929\right)$ and late stage HSC $\left(\mathrm{CD} 45^{+} / \mathrm{CD} 34^{+} / \mathrm{CD} 133^{-}, P=0.9479\right)$ subtypes were observed, the differences between male and female were still not be marked [51].

Obstetric history does have a higher effect on UCB content, with number of pregnancies having a marked effect with (i) significantly decreasing UCB TNC in subsequent pregnancies $(P<0.0001)$, (ii) similarly decreasing early stage HSC populations, dendritic cells expressing MHC class II surface antigens ( $\left.\mathrm{Lin}^{-} / \mathrm{CD} 11 \mathrm{c}^{+} / \mathrm{HLA}-\mathrm{DR}^{+}\right)$, and activated T-cells $\left(\mathrm{CD} 45^{+} / \mathrm{CD}^{2} 6^{+} / \mathrm{CD}^{-}{ }^{-}\right.$) (all $P$ value of $<0.001$ ) [51].

Infant birth weight also impacts on UCB cellularity. In a study of birth weights from $2.585 \mathrm{~kg}$ to $4.425 \mathrm{~kg}$ (average $3.571 \mathrm{~kg} \pm \mathrm{SD} 0.44)$, data illustrates that babies with lowest birth weight also have lowest TNC $(P<0.0001)$ but exceptions can be found. Birth weight also impacts on HSC concentrations, especially at mid-stage HSC. As birth weight rises, HSC concentration as well $(P<0.001)$. A birth weight between 3.25 and $3.75 \mathrm{~kg}$ gives an optimum yield of dendritic cells expressing MHC class II (Lin1/CD11 $\mathrm{c}^{+} / \mathrm{HLA}^{-\mathrm{DR}^{+}}$) and T-cells similarly rise $(P<0.001)[51]$.

In investigating pregnancy length, the standard expected of a 40 -week-period (280 days) is not always achieved. Our work shows that babies born early or late by only a few weeks can have differing levels of cellularity in the cord blood. TNC levels of early and late children are lower $(P<0.001)$. Late stage gestational periods results in higher levels of T-cells and late-stage HSC $(P<0.001)$. On the other hand, optimal Bcell levels require a gestational length of 38-40 weeks [51].

In many societies, the family decision to wait to have children has been questioned from a developmental point of view. In our work, mother's age at parturition between ages 18-43 has a significant effect on the UCB content. 
TABLE 1: Important surface markers for quantification of human umbilical cord blood content.

\begin{tabular}{|c|c|c|}
\hline $\begin{array}{l}\text { Human CD } \\
\text { antigens }\end{array}$ & Cell types expressed on & CD function \\
\hline CD3 & T cells, thymocyte subset & With TCR, TCR surface expression/signal transduction \\
\hline $\mathrm{CD} 4$ & Thymocyte subset, T subset, monocytes, macrophages & $\begin{array}{l}\text { MHC class II coreceptor, HIV receptor, T cell } \\
\text { differentiation/activation }\end{array}$ \\
\hline CD8 & Thymocyte subset, T subset, NK & $\begin{array}{l}\text { MHC class I coreceptor, receptor for some mutated } \\
\text { HIV-1, T cell differentiation/activation }\end{array}$ \\
\hline CD11c & DC, myeloid cells, NK, B, T subset & Binds CD54, fibrinogen, and iC3b \\
\hline CD17 & Neutrophils, mono, platelets & Lactosylceramide \\
\hline CD19 & B, FDC & $\begin{array}{l}\text { Complex w/CD21 and CD } 81, \text { BCR coreceptor, B cell } \\
\text { activation/differentiation }\end{array}$ \\
\hline $\mathrm{CD} 25$ & $\mathrm{~T}^{\text {act }}, \mathrm{B}^{\text {act }}$, lymph progenitors & IL-2R $\alpha, \mathrm{w} / \mathrm{IL}-2 \mathrm{R} \beta$, and $\gamma$ to form high affinity complex \\
\hline $\mathrm{CD} 34$ & $\begin{array}{l}\text { Haematopoietic precursors, capillary endothelial, embryonic } \\
\text { fibroblasts }\end{array}$ & Stem cell marker, adhesion, CD62L receptor \\
\hline CD45 & Haematopoietic cells, multiple isoforms from alternative splicing & Tyrosine phosphatase, enhanced TCR, and BCR signals \\
\hline CD56 & $\begin{array}{l}\text { NK, T subset, neurones, some large granular lymphocyte } \\
\text { leukemias, myeloid leukemias }\end{array}$ & Adhesion \\
\hline CD123 & $\begin{array}{l}\text { Lymph subset, basophils, haematopoietic progenitors, } \\
\text { macrophages, DC, megakaryocytes }\end{array}$ & IL-3R $\alpha$, w/CDw131 \\
\hline CD133 & Haematopoietic stem cell subset, epithelial, endothelial & Adhesion \\
\hline $7 \mathrm{ADD}$ & Nucleic acid attachment & Apoptosis marker and viability assessment \\
\hline $\operatorname{Lin} 1$ & $\begin{array}{l}\text { CD3; T-lymphocytes } \\
\text { CD14; monocytes, macrophages, neutrophils and eosinophils, } \\
\text { CD16; NK-lymphocytes, macrophages, cultured monocytes and } \\
\text { neutrophils, } \\
\text { CD19/CD20; B-lymphocytes, } \\
\text { CD56; activated and resting NK-lymphocytes }\end{array}$ & $\begin{array}{l}\text { With TCR, TCR surface expression/signal transduction. } \\
\text { Pattern recognition receptor } \\
\text { Fc receptor } \\
\text { B-cell coreceptor } \\
\text { Adhesion molecule }\end{array}$ \\
\hline HLA-DR & Macrophages, B-cells and dendritic cells & MHC class II cell surface marker \\
\hline
\end{tabular}

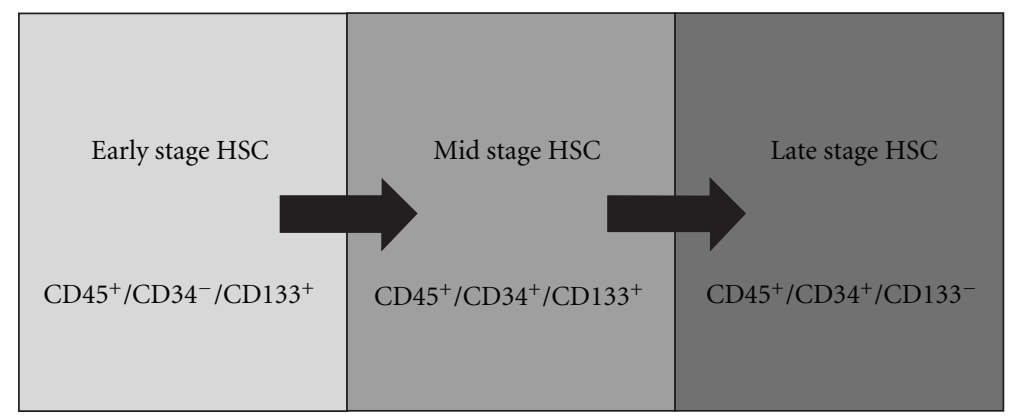

FIGURE 1: Subtyping of HSCs. HSC differentiation has a specific pattern from early to mid to late stages defined by surface antigen expression.

As mother's age increases, HSC concentration reduces, particularly late stage $\mathrm{HSC}(P<0.0001)$, as does regulatory T-cells $\left(\mathrm{CD} 45^{+} / \mathrm{CD}^{+} / \mathrm{CD}^{+}\right)$, and indeed all lymphocytes $(P<0.001)$. However, mother's under the age of 20 and over the age of 37 tend to have babies with lower TNC than mother's that lie within that age range $(P<0.001)[51]$.
Therefore, results would indicate that the most likely units to be useful for UCB banking and transplantation come from full term larger babies who are born to younger mothers with few previous pregnancies [51]. These findings could be of significant interest to immunologists, since lower TNC and fewer lymphocytes may have an impact on the health 
of the child itself. Since several obstetric factors affect T-cell concentration, infants born late into larger families may warrant further immunological investigation, particularly to older mothers, but conventional wisdom that prematurity is a negative influence on immunity is upheld when UCB units of full term large babies have good levels of lymphocytes [54-56].

Despite the interesting data on obstetric factors and cord blood content, many of the studies have been country specific. This observation highlights the need for a true international study to evaluate UCB content in terms of regional variations, including ethnicity, average height and weight of the mother-since it is well known that in some Asian countries the female average height is lower, and finally differences between vaginal and caesarean delivery methods.

\section{Approaches to Improve Cord Blood Stem Cell Expansion and Engraftment}

Increased cell dose and improved homing are two major concerns prevailing in efforts to overcome engraftment delay following UCBT [27]. There is a strong association between these strategies to reconstitute hematopoetic system after UCBT which are discussed here. There are many unknown aspects about the interaction of hematopoietic components. However, designing ex-vivo experiments based on in vivo conditions shall naturally lead to more findings. Expansion of UCB-HSCs is an approach to increase cell dose and make UCB-HSC applicable for adult transplantation. Ex vivo expansion is performed through various ways: modifications in liquid culture, stromal coculture, and perfusion in bioreactors [57]. Reduced intensity conditioning (RIC) regimens, double cord blood transplantation, direct intra-BM injection of $\mathrm{CB}$ grafts, notch ligand expansion, as well as SDF1/CXCR4 targeting represent new promising approaches to shorten CBT engraftment time [12].

4.1. Cytokine-Mediated Expansion. A wide variety of cytokine cocktails, growth factors, or other biological mediators in liquid culture have been assessed. Cytokines such as stem cell factor (SCF), interleukin (IL)-3, IL-6 and granulocyte colony-stimulating factor (G-CSF), thrombopoietin (TPO), and Flt-3 ligand (FL) have been extensively used with various dose or culture length [58]. However, the heterogeneity of $\mathrm{CB}$ samples and experimental conditions causes inconsistency among results and there is no specific growth factor cocktail that is universally applicable. Recently, a two-step expansion system proposed by McNiece et al. [59] yielded more than 400-fold increase in TNC and 20-fold increase in CD $34^{+}$cells, which is more effective than single step expansion [60]. Cytokine-based expansion has not proved any definitive evidence for stem cell expansion for clinical purposes.

4.2. Neuropeptides. The complex hematopoiesis network consists of nonhematopoietic cells, hematopoietic cells, as well as various ranges of biological mediators such as hormones, cytokines, and neurotransmitters. However, until recently, enough evidence regarding the role of neuropeptides on UCB CD $34^{+}$cells was not available. Research had indicated that inclusion of biological mediators other than cytokines, such as neuropeptides would be valuable for optimization of UCB-HSC ex vivo expansion and shortening engraftment time [61]. Accordingly, once the role of substance P (SP) and calcitonin-gene-related neuropeptides (CGRP) on the expansion of UCB CD34 ${ }^{+}$cells was investigated [62], results showed maximum expansion in $10^{-9} \mathrm{M}$ of neuropeptides in short time culture. Synergistic and antagonistic effects of both SP and CGRP were dominant at $10^{-9} \mathrm{M}$ and $10^{-7} \mathrm{M}$ dose on total nucleated cells and CD $34^{+}$ $\mathrm{CD}^{-} 8^{-}$cells, respectively [62]. Interestingly, concentration $10^{-9} \mathrm{M}$ of SP leds to optimal production of SCF and IL1 in BM stroma [63]. It seems that the proliferation of immuohematopoietic cells resulted as consequence of these interactions. Based on these preliminary findings, identifying further neuropeptide and UCB-HSC interactions would be helpful to achieve an optimum growth factor cocktail for expansion.

4.3. Coculture and Coinfusion with Stromal Cells. Growth factor cocktails use in ex vivo expansion partially compensates lack of natural hematopoietic microenvironment. Mesenchymal stem cells (MSCs)/stromal coculture is an optional modification to resemble the hematopoietic microenvironment. Coinfusion of MSCs - which is suitable for immunomodulation and prevention of GVHD-and employment of HSCs is another potential strategy to facilitate engraftment. Furthermore, immunomodulatory properties of MSCs make them a desirable cell for this purpose. There is little controversial evidence about UCB-derived MSCs and most experiments are performed on marrowderived cells. Hematopoetic engraftment is supported by MSC through neurogenic and angiogenic mechanisms. Therefore, it has been proposed that coinfusion of MSC and hematopoietic cells accelerate engraftment of UCB $[58,64]$.

4.4. Tetraethylenepentamine- (TEPA-) Mediated Expansion. Reduction of free copper content and oxidative stress level of HSCs is the main suggested reason for induction of $e x-$ vivo expansion of HSCs by tetraethylenepentamine (TEPA) treatment. An increase of 89 -fold in $\mathrm{CD}^{+} 4^{+}$cells was achieved by polyamine copper chelator, -TEPA-in Peled et al. experiment [65]. TEPA mediated expansion studies are in phase I/II clinical trials [12].

4.5. Notch Ligand-Based Expansion. Notch-1 gene expressed in $\mathrm{CD}_{3} 4^{+}$hematopoietic precursor cells is involved in self-renewal of repopulating cells. For expansion in static culture an immobilized, engineered notch ligand Delta1 with cytokine cocktail (SCF, FL, IL-6, TPO, and IL-3) was investigated in experiment [66]. Immobilized notch ligand results in improved immune reconstitution and enhanced cell number and phase I/II clinical trials are underway. Delaney et al. showed that coinfusion of unmanipulated UCB and notch-mediated ex vivo expanded UCB had faster neutrophil engraftment, 16 days, compared to infusion of 
unmanipulated double UCBT, which took 26 days [66]. More clinical trials are required to support these results.

4.6. Adhesion Molecules for HSC Homing. Adhesion molecules are involved in the regulation of survival, proliferation and differentiation of progenitor cells. This might occur through interaction with microenvironment components [67] and biological mediators such as cytokines, chemokines, and neuropeptides. Secretion of stromal-derived factor (SDF)-1 by BM stromal cells is crucial for retention/homing of HSC in BM [26]. Additionally, involvement of this axis in survival and proliferation of HSCs has been shown [12]. For HSC engraftment, CXCR4 response to SDF1 and SDF-1 expression in BM microenvironment is important [26]. To improve homing of HSC following CBT, several approaches have been considered. Inhibition of enzymatic activity of CD26/Dipeptidylpeptidase IV (DPPIV) avoids truncation of SDF-1/CXCL12-exclusive ligand for CXCR4, and consequently results in acceleraed UCB-HSC engraftment. Additionally, in order to increase the responsiveness of SDF1/CXCR4, ex vivo priming of HSCs prior to transplantation with small molecules including C3 complement fragments, fibronectin, fibrinogen, and hyaluronic acid has been suggested to improve homing/engraftment of UCBHSCs [26].

Recently, SP and CGRP neuropeptide treated CB stem cells showed increased percentage of CD $34^{+} /$CXCR4 [68], CD49e, and CD44 [69] subsets in neuropeptide-cytokine treated cells compared to cytokine-treated cells in short time culture, as well as a resistance to frequency decline. Accordingly, since actions of neuropeptides on hematopoeisis are less known, more investigation to clarify underlying mechanisms is required.

\section{Cord Blood Stem Cells Transplantation: A Potential Cure for Blood Diseases}

5.1. Main Interventions in Malignant and Nonmalignant Blood Diseases. In children and adults with hematologic malignancies (i.e., lymphoid- and myeloid-), most clinical studies were performed in an unrelated donor setting and reported that the TNC dose contained in a UCB unit has a profound impact on engraftment and an effect on infection risk and survival $[8,9,19,20,22,23,70,71]$. In addition, the degree of HLA matching as well as the indication of UCBT according the cancer stage seemed to have an independent impact on outcome (i.e., recipients who had more than two HLA mismatches and/or with advancedstage malignant diseases experienced the worst outcomes) $[4,22,23]$. Over the past two decades, important changes (e.g., better selection of UCB donor units, greater selection of suitable transplantation recipients, more supportive experienced care) have improved outcomes $[10,12]$. In hematologic nonmalignancies, such as thalassemia and sickle cell disease (SCD), it has been reported that graft rejection as well as delayed or failed engraftment after UCBT, represent the two major barriers, although often counter-balanced by the benefit of lower risk GVHD [8, 20, 72-74].
Here, we provide two relevant examples of blood diseases for which UCBT has been frequently reported. Thereby, we will discuss the case of leukemia, especially acute leukemia, as an example of UCBT in blood malignancy as well as thalassemia, especially thalassemia major, as an example of nonmalignant disorder.

5.2. Case of Leukemia. UCBT outcome for leukemia is widely documented since the nineties of the last century, mostly in pediatric patients with acute leukemia (i.e., $30-50 \%$ in most series) [7, 8, 20, 21, 70, 75, 76]. However, outcomes of other subsets of the disease (e.g., chronic myeloid leukemia (CML), myelodysplastic syndrome (MDS) formerly known as pre-leukemia) after UCBT are mainly limited by the number of patients [77-83]. Overall, data supports the utilization of UCB as an alternative source of HSC for patients with low- and high-risk leukemia and/or with no HLA-matched unrelated donor. Nevertheless, in patients with CML, low engraftment-certainly due to small cell dose-and moderate overall survival (40-60\%) was observed after UBCT and, in spite of low relapse rates (about 10\%), UBCT is not highly desired [79-81].

In acute leukemia patients, the neutrophil engraftment rate was reported to be about $60-80 \%$, the TRM rate of about $44 \%$, the relapse rate of approximately $20-40 \%$, and the event- (leukemia-) free survival (EFS) rate at 2 years was ranged between 30 and 50\% [9, 19, 84, 85]. In children with acute leukemia who received better HLA-matched grafts and higher cell dose achieved better survival [85]. In adults with acute leukemia, recent studies [33, 34, 86-90] showed that outcomes after UCBT were manifested by lower risk of TRM and similar EFS compared to unrelated (matched or mismatched) donor BM after myeloablative conditioning (cyclophosphamide/total body irradiation). Interestingly, double UBCT can overcome the cell dose limitation imposed by UCB grafts in adults while favoring a lower relapse risk [91].

Besides, reports evaluating the outcomes of patients with acute myeloid leukemia (AML) after UCBT showed promises according to the graft selection and disease stage at transplantation $[92,93]$. Indeed, it was shown that myeloablative UCBT, influenced by TNC, achieved neutrophil recovery (94\%-96\%), sustained platelet recovery $(73 \%-89 \%)$, EFS rate of about $77 \%$ at 2 years and about $37 \%$ at 4 years, incidence of TRM of about $39 \%$, and relapse rate of approximately $19 \%$ at 2 years $[24,94]$.

In nonmyeloablative settings, studies are required to assess the outcomes leukemia outcomes after reducedintensity conditioning [24, 94].

Eventually, overall data support the utilization of UCB as an alternative source of HSCT for patients with acute leukemia who lack a suitable related donor.

5.3. Case of Thalassemia. UCBT become a valuable alternative to overcome lack of both safety (i.e., GVHD) and HLA-identical sibling donor associated with conventional BMT, which initially demonstrated (about 30 years ago) a curative potential for thalassemia major, the severe form of this genetic hemoglobinopathy [95]. 
In one retrospective survey of sibling/related donor cord blood transplantation, about $21 \%$ children with thalassemia developed graft rejection after transplantation, the EFS was approximately 79\%, acute and chronic GVHD were low (about 6\%) and, remarkably, none of the patients $(n=33)$ died [73]. Interestingly, the graft rejection was often associated with the type of conditioning regimen. Thereby, a conditioning regimen of busulfan (BU) and cyclophosphamide (CY), with or without antithymocyte globulin (ATG), had a significant association with graft rejection after UCB transplantation for thalassemia [73]. However, children with thalassemia prepared for CBT with a combination of $\mathrm{BU}$, fludarabine (Flu) or CY, and thiotepa (TT) and received cyclosporine alone for postgrafting immunosuppression, exerted very positive outcomes (high EFS rate enhanced from $62 \%$ to $94 \%$ if CY was used instead of Fly; no acute or chronic GVHD) [73]. UCBT using unrelated donors as a potential cure for thalassemia requires large series of patients [96]. Thalassemiarecipients typically received unrelated cord blood units with 1 or 2 HLA mismatches and are prepared with a conventional combination of BU/CY/ATG. Most studies, mainly in children, showed good outcomes after unrelated UCBT: limited chronic GVHD, relatively rapid and good neutrophil and platelet count recovery, low TRM and high EFS rate [97, 98]. Graft failure or was autologous recovery were the main limitations.

Thus, the development of UCB as an alternate source of hematopoietic cells in transplantation for thalassemia must be linked to an effort to increase the UCB inventory with high-quality units collected from an ethnically representative population.

\section{Conclusion}

It is difficult to compare older transplantation outcome reports with more recent studies (i.e., comprehensive metaanalysis) because of changes mainly related to (i) stem cell sources (UCB unit characteristics), (ii) year of transplantation, (iii) time from diagnosis to transplantation, (iv) disease stage, (v) methodology of HLA-typing, (vi) conditioning regimen formulation, and (vii) standard of the cell dose that must be available in a single UCB unit to be infused.

However, UCBT offers an attractive alternative to BMT, in particular because of the low incidence of GVHD. Indeed, although UBCT is associated with a greater risk of graft rejection, due in part to a restricted number of hematopoietic stem cells, nevertheless, this risk can be overcome in part by selecting UCB units that contain a large number of cells and those that are closely matched at the HLA loci.

Alternatively, the use of double UCBT from unrelated donors or the potential collection of HSCs from human placenta might be useful approaches to optimize the donor hematopoietic stem cell content. Interestingly, recent results show excellent outcomes after HLA-identical sibling UCBT, stressing the importance of collecting cord blood in families when a child is affected by blood disorders. Eventually, recent studies reported that combination of UCB unit collected after a sibling birth with a marrow harvested from the same donor presented excellent results exerted by both low rates of GVHD and graft rejection. Most recent studies aim to optimize UCBT and promising results were obtained once the cell dose was increased and the homing improved taking into consideration several microenvironmental factors (e.g., cytokines, neuropeptides) and cells (e.g., mesenchymal stem cells).

The field of human hematotherapy was transformed with the advent of bone marrow replacement and augmented by the application of umbilical cord blood units. The increasing number of cord blood banks around the world makes sourcing of units an increased potential and has begun to slowly outweigh the need for bone marrow registries. Despite this, the costs involved are still unaffordable to many countries, not least in developing nations. Changes in the processing procedures, our knowledge of the true content of cord blood from children of different backgrounds, and from mothers of different ages and heatlh status, and the advent of new technologies will hopefully make availability of umbilical cord blood transplantation a reality in every nation in the future.

\section{Authors' Contribution}

All authors have equally contributed to this work.

\section{Acknowledgments}

The authors are grateful to Dr. Abder Menaa, M. D., for his suggestions after pertinent revision of this paper. They also thank Saba Habibollah, Christina Basford, and Nico Forraz for data analysis.

\section{References}

[1] J. Halbrecht, "Transfusion with placental blood," The Lancet, vol. 233, no. 6022, pp. 202-203, 1939.

[2] M. Ende and N. Ende, "Hematopoietic transplantation by means of fetal (cord) blood. A new method.," Virginia Medical Monthly, vol. 99, no. 3, pp. 276-280, 1972.

[3] E. Gluckman, H. E. Broxmeyer, A. D. Auerbach et al., "Hematopoietic reconstitution in a patient with Fanconi's anemia by means of umbilical-cord blood from an HLAidentical sibling," New England Journal of Medicine, vol. 321, no. 17, pp. 1174-1178, 1989.

[4] H. E. Broxmeyer and F. O. Smith, "Cord blood hematopoietic cell transplantation," in Thomas' Hematopoietic Cell Transplantation, pp. 559-576, Wiley-Blackwell, Malden, Mass, USA, 2009.

[5] R. Hough and V. Rocha, "Transplant outcomes in acute leukemia (II)," Seminars in Hematology, vol. 47, no. 1, pp. 51$58,2010$.

[6] M. L. MacMillan, M. C. Walters, and E. Gluckman, "Transplant outcomes in bone marrow failure syndromes and hemoglobinopathies," Seminars in Hematology, vol. 47, no. 1, pp. 37-45, 2010.

[7] J. E. Wagner, N. A. Kernan, M. Steinbuch, H. E. Broxmeyer, and E. Gluckman, "Allogeneic sibling umbilical-cordblood transplantation in children with malignant and nonmalignant disease," The Lancet, vol. 346, no. 8969, pp. $214-$ 219, 1995. 
[8] E. Gluckman, V. Rocha, A. Boyer-Chammard et al., "Outcome of cord-blood transplantation from related and unrelated donors. Eurocord transplant group and the European blood and marrow transplantation group," New England Journal of Medicine, vol. 337, no. 6, pp. 373-381, 1997.

[9] F. Locatelli, V. Rocha, C. Chastang et al., "Factors associated with outcome after cord blood transplantation in children with acute leukemia," Blood, vol. 93, no. 11, pp. 3662-3671, 1999.

[10] V. Rocha and E. Gluckman, "Improving outcomes of cord blood transplantation: HLA matching, cell dose and other graft- and transplantation-related factors," British Journal of Haematology, vol. 147, no. 2, pp. 262-274, 2009.

[11] H. E. Broxmeyer, "Umbilical cord transplantation: epilogue," Seminars in Hematology, vol. 47, no. 1, pp. 97-103, 2010.

[12] V. Rocha and H. E. Broxmeyer, "New approaches for improving engraftment after cord blood transplantation.," Biology of Blood and Marrow Transplantation, vol. 16, supplement 1, pp. S126-S132, 2010.

[13] G. Cohen, S. L. Carter, K. I. Weinberg et al., "Antigen-specific T-lymphocyte function after cord blood transplantation," Biology of Blood and Marrow Transplantation, vol. 12, no. 12, pp. 1335-1342, 2006.

[14] V. Rocha and F. Locatelli, "Searching for alternative hematopoietic stem cell donors for pediatric patients," Bone Marrow Transplantation, vol. 41, no. 2, pp. 207-214, 2008.

[15] M. Eapen, P. Rubinstein, M. J. Zhang et al., "Outcomes of transplantation of unrelated donor umbilical cord blood and bone marrow in children with acute leukaemia: a comparison study," The Lancet, vol. 369, no. 9577, pp. 1947-1954, 2007.

[16] V. K. Prasad and J. Kurtzberg, "Umbilical cord blood transplantation for non-malignant diseases," Bone Marrow Transplantation, vol. 44, no. 10, pp. 643-651, 2009.

[17] E. Gluckman, V. Rocha, I. Ionescu et al., "Results of unrelated cord blood transplant in Fanconi anemia patients: risk factor analysis for engraftment and survival," Biology of Blood and Marrow Transplantation, vol. 13, no. 9, pp. 1073-1082, 2007.

[18] A. Willasch, W. Hoelle, H. Kreyenberg et al., "Outcome of allogeneic stem cell transplantation in children with nonmalignant diseases," Haematologica, vol. 91, no. 6, pp. 788794, 2006.

[19] G. Michel, V. Rocha, S. Chevret et al., "Unrelated cord blood transplantation for childhood acute myeloid leukemia: a Eurocord Group analysis," Blood, vol. 102, no. 13, pp. 42904297, 2003.

[20] P. Rubinstein, C. Carrier, A. Scaradavou et al., "Outcomes among 562 recipients of placental-blood transplants from unrelated donors," New England Journal of Medicine, vol. 339, no. 22, pp. 1565-1577, 1998.

[21] J. E. Wagner, J. N. Barker, T. E. DeFor et al., “Transplantation of unrelated donor umbilical cord blood in 102 patients with malignant and nonmalignant diseases: influence of CD34 cell dose and HLA disparity on treatment-related mortality and survival," Blood, vol. 100, no. 5, pp. 1611-1618, 2002.

[22] V. Rocha, G. Sanz, and E. Gluckman, "Umbilical cord blood transplantation," Current Opinion in Hematology, vol. 11, no. 6, pp. 375-385, 2004.

[23] E. Gluckman, V. Rocha, W. Arcese et al., "Factors associated with outcomes of unrelated cord blood transplant: guidelines for donor choice," Experimental Hematology, vol. 32, no. 4, pp. 397-407, 2004.
[24] C. G. Brunstein, J. N. Barker, D. J. Weisdorf et al., "Umbilical cord blood transplantation after nonmyeloablative conditioning: impact on transplantation outcomes in 110 adults with hematologic disease," Blood, vol. 110, no. 8, pp. 3064-3070, 2007.

[25] J. N. Barker, D. J. Weisdorf, T. E. DeFor et al., "Transplantation of 2 partially HLA-matched umbilical cord blood units to enhance engraftment in adults with hematologic malignancy," Blood, vol. 105, no. 3, pp. 1343-1347, 2005.

[26] C. Delaney, M. Z. Ratajczak, and M. J. Laughlin, "Strategies to enhance umbilical cord blood stem cell engraftment in adult patients," Expert Review of Hematology, vol. 3, no. 3, pp. 273$283,2010$.

[27] A. Stanevsky, A. Shimoni, R. Yerushalmi, and A. Nagler, "Cord blood stem cells for hematopoietic transplantation," Stem Cell Reviews and Reports, vol. 7, no. 2, pp. 425-433, 2011.

[28] J. A. Gutman, S. R. Riddell, S. McGoldrick, and C. Delaney, "Double unit cord blood transplantation: who wins-and why do we care?" Chimerism, vol. 1, no. 1, pp. 21-22, 2010.

[29] V. Rocha, J. E. Wagner, K. A. Sobocinski et al., "Graft-versushost disease in children who have received a cord blood or bone marrow transplant from an HLA-identical sibling," New England Journal of Medicine, vol. 342, no. 25, pp. 1846-1854, 2000.

[30] H. M. Lazarus, "Acute leukemia in adults: novel allogeneic transplant strategies," Hematology, vol. 17, supplement 1, pp. 47-51, 2012.

[31] M.-J. Zhang, S. M. Davies, B. M. Camitta, B. Logan, K. Tiedemann, and M. Eapen, "Comparison of outcomes after HLA-matched sibling and unrelated donor transplantation for children with high-risk acute lymphoblastic leukemia," Biology of Blood and Marrow Transplantation, vol. 18, no. 8, pp. 12041210, 2012.

[32] L. E. Perez, "Outcomes from unrelated donor hematopoietic stem cell transplantation," Cancer Control, vol. 18, no. 4, pp. 216-221, 2011.

[33] M. Eapen, V. Rocha, G. Sanz et al., "Effect of graft source on unrelated donor haemopoietic stem-cell transplantation in adults with acute leukaemia: a retrospective analysis," The Lancet Oncology, vol. 11, no. 7, pp. 653-660, 2010.

[34] M. J. Laughlin, M. Eapen, P. Rubinstein et al., "Outcomes after transplantation of cord blood or bone marrow from unrelated donors in adults with leukemia," New England Journal of Medicine, vol. 351, no. 22, pp. 2265-2275, 2004.

[35] J. Kurtzberg, M. Laughlin, M. L. Graham et al., "Placental blood as a source of hematopoietic stem cells for transplantation into unrelated recipients," New England Journal of Medicine, vol. 335, no. 3, pp. 157-166, 1996.

[36] A. Ghavamzadeh, K. Alimoghaddam, A. Naderi et al., "Outcome of related and unrelated cord-blood transplantation in children at hematopoietic stem cell transplantation research center of Shariati Hospital," International Journal of Hematology-Oncology and Stem Cell Research, vol. 3, no. 1, pp. 17-20, 2009.

[37] J. N. Barker, T. P. Krepski, T. E. DeFor, S. M. Davies, J. E. Wagner, and D. J. Weisdorf, "Searching for unrelated donor hematopoietic stem cells: availability and speed of umbilical cord blood versus bone marrow," Biology of Blood and Marrow Transplantation, vol. 8, no. 5, pp. 257-260, 2002.

[38] H. E. Broxmeyer, E. Gluckman, A. Auerbach et al., "Human umbilical cord blood: a clinically useful source of transplantable hematopoietic stem/progenitor cells," International Journal of Cell Cloning, vol. 8, supplement 1, pp. 76-91, 1990. 
[39] S. J. Deacock, A. P. Schwarer, J. Bridge, J. R. Batchelor, J. M. Goldman, and R. I. Lechler, "Evidence that umbilical cord blood contains a higher frequency of HLA class II-specific alloreactive $\mathrm{T}$ cells than adult peripheral blood: a limiting dilution analysis," Transplantation, vol. 53, no. 5, pp. 1128 1134, 1992.

[40] M. G. Roncarolo, M. Bigler, E. Ciuti, S. Martino, and P. A. Tovo, "Immune responses by cord blood cells," Blood Cells, vol. 20, no. 2-3, pp. 573-586, 1994.

[41] A. Bensussan, E. Gluckman, S. El Marsafy et al., "BY55 monoclonal antibody delineates within human cord blood and bone marrow lymphocytes distinct cell subsets mediating cytotoxic activity," Proceedings of the National Academy of Sciences of the United States of America, vol. 91, no. 19, pp. 9136-9140, 1994.

[42] X. J. Huang, D. H. Liu, K. Y. Liu et al., “Treatment of acute leukemia with unmanipulated HLA-mismatched/haploidentical blood and bone marrow transplantation," Biology of Blood and Marrow Transplantation, vol. 15, no. 2, pp. 257-265, 2009.

[43] F. Ciceri, M. Labopin, F. Aversa et al., "A survey of fully haploidentical hematopoietic stem cell transplantation in adults with high-risk acute leukemia: a risk factor analysis of outcomes for patients in remission at transplantation," Blood, vol. 112, no. 9, pp. 3574-3581, 2008.

[44] F. Aversa, A. Terenzi, A. Tabilio et al., "Full haplotype-mismatched hematopoietic stem-cell transplantation: a phase II study in patients with acute leukemia at high risk of relapse," Journal of Clinical Oncology, vol. 23, no. 15, pp. 3447-3454, 2005.

[45] E. Naparstek, M. Delukina, R. Or et al., "Engraftment of marrow allografts treated with Campath-1 monoclonal antibodies," Experimental Hematology, vol. 27, no. 7, pp. 1210$1218,1999$.

[46] T. B. Prigozhina, O. Gurevitch, and S. Slavin, "Nonmyeloablative conditioning to induce bilateral tolerance after allogeneic bone marrow transplantation in mice," Experimental Hematology, vol. 27, no. 10, pp. 1503-1510, 1999.

[47] L. Ruggeri, A. Mancusi, M. Capanni et al., "Donor natural killer cell allorecognition of missing self in haploidentical hematopoietic transplantation for acute myeloid leukemia: challenging its predictive value," Blood, vol. 110, no. 1, pp. 433-440, 2007.

[48] K. Perruccio, A. Tosti, E. Burchielli et al., "Transferring functional immune responses to pathogens after haploidentical hematopoietic transplantation," Blood, vol. 106, no. 13, pp. 4397-4406, 2005.

[49] C. P. McGuckin, N. Forraz, M. O. Baradez et al., "Production of stem cells with embryonic characteristics from human umbilical cord blood," Cell Proliferation, vol. 38, no. 4, pp. 245-255, 2005.

[50] C. Basford, N. Forraz, and C. McGuckin, "Optimized multiparametric immunophenotyping of umbilical cord blood cells by flow cytometry," Nature Protocols, vol. 5, no. 7, pp. 13371346, 2010.

[51] C. P. McGuckin, C. Basford, K. Hanger, S. Habibollah, and N. Forraz, "Cord blood revelations: the importance of being a first born girl, big, on time and to a young mother!," Early Human Development, vol. 83, no. 12, pp. 733-741, 2007.

[52] F. Mancinelli, A. Tamburini, A. Spagnoli et al., "Optimizing umbilical cord blood collection: impact of obstetric factors versus quality of cord blood units," Transplantation Proceedings, vol. 38, no. 4, pp. 1174-1176, 2006.
[53] C. P. McGuckin, D. Pearce, N. Forraz, J. A. Tooze, S. M. Watt, and R. Pettengell, "Multiparametric analysis of immature cell populations in umbilical cord blood and bone marrow," European Journal of Haematology, vol. 71, no. 5, pp. 341-350, 2003.

[54] V. Tommiska, K. Heinonen, S. Ikonen et al., "A national shortterm follow-Up study of extremely low birth weight infants born in Finland in 1996-1997." Pediatrics, vol. 107, no. 1, p. E2, 2001.

[55] B. Adkins, "T-cell function in newborn mice and humans," Immunology Today, vol. 20, no. 7, pp. 330-335, 1999.

[56] J. Li, D. R. Barreda, Y. A. Zhang et al., "B lymphocytes from early vertebrates have potent phagocytic and microbicidal abilities," Nature Immunology, vol. 7, no. 10, pp. 1116-1124, 2006.

[57] Y. Liao, M. B. Geyer, A. J. Yang, and M. S. Cairo, "Cord blood transplantation and stem cell regenerative potential," Experimental Hematology, vol. 39, no. 4, pp. 393-412, 2011.

[58] S. S. Tung, S. Parmar, S. N. Robinson, M. De Lima, and E. J. Shpallemail, "Ex vivo expansion of umbilical cord blood for transplantation," Best Practice \& Research Clinical Haematology, vol. 23, no. 2, pp. 245-257, 2010.

[59] I. McNiece, D. Kubegov, P. Kerzic, E. J. Shpall, and S. Gross, "Increased expansion and differentiation of cord blood products using a two-step expansion culture," Experimental Hematology, vol. 28, no. 10, pp. 1181-1186, 2000.

[60] E. J. Shpall, R. Quinones, R. Giller et al., "Transplantation of ex vivo expanded cord blood," Biology of Blood and Marrow Transplantation, vol. 8, no. 7, pp. 368-376, 2002.

[61] M. Ebtekar, S. Shahrokhi, and K. Alimoghaddam, Characteristics of Cord Blood Stem Cells: Role of Substance P, (SP) and Calcitonin Gene-Related Peptide (CGRP), Stem Cells and Cancer Stem Cells, vol. 2, Springer Netherlands, Heidelberg, Germany, 2012.

[62] S. Shahrokhi, M. Ebtekar, K. Alimoghaddam et al., "Substance $\mathrm{P}$ and calcitonin gene-related neuropeptides as novel growth factors for ex vivo expansion of cord blood CD34+ hematopoietic stem cells," Growth Factors, vol. 28, no. 1, pp. 66-73, 2010.

[63] P. Rameshwar, D. Ganea, and P. Gascon, "In vitro stimulatory effect of Substance P on hematopoiesis," Blood, vol. 81, no. 2, pp. 391-398, 1993.

[64] D. McKenna and J. Sheth, "Umbilical cord blood: current status and promise for the future," Indian Journal of Medical Research, vol. 134, pp. 261-269, 2011.

[65] T. Peled, J. Mandel, R. N. Goudsmid et al., "Pre-clinical development of cord blood-derived progenitor cell graft expanded ex vivo with cytokines and the polyamine copper chelator tetraethylenepentamine," Cytotherapy, vol. 6, no. 4, pp. 344-355, 2004.

[66] C. Delaney, S. Heimfeld, C. Brashem-Stein, H. Voorhies, R. L. Manger, and I. D. Bernstein, "Notch-mediated expansion of human cord blood progenitor cells capable of rapid myeloid reconstitution," Nature Medicine, vol. 16, no. 2, pp. 232-236, 2010.

[67] C. M. Verfaillie, "Adhesion receptors as regulators of the hematopoietic process," Blood, vol. 92, no. 8, pp. 2609-2612, 1998.

[68] S. Shahrokhi, M. Ebtekar, K. Alimoghaddam et al., "Communication of substance $\mathrm{P}$, calcitonin-gene-related neuropeptides and chemokine receptor 4 (CXCR4) in cord blood hematopoietic stem cells," Neuropeptides, vol. 44, no. 5, pp. 385-389, 2010. 
[69] S. Shahrokhi, K. Alimoghaddam, M. Ebtekar et al., "Effects of neuropeptide substance $\mathrm{P}$ on the expression of adhesion molecules in cord blood hematopoietic stem cells," Annals of Hematology, vol. 89, no. 12, pp. 1197-1205, 2010.

[70] M. J. Laughlin, J. Barker, B. Bambach et al., "Hematopoietic engraftment and survival in adult recipients of umbilicalcord blood from unrelated donors," New England Journal of Medicine, vol. 344, no. 24, pp. 1815-1822, 2001.

[71] J. N. Barker, S. M. Davies, T. DeFor, N. K. C. Ramsay, D. J. Weisdorf, and J. E. Wagner, "Survival after transplantation of unrelated donor umbilical cord blood is comparable to that of human leukocyte antigen-matched unrelated donor bone marrow: results of a matched-pair analysis," Blood, vol. 97, no. 10, pp. 2957-2961, 2001.

[72] F. O. Pinto and I. Roberts, "Cord blood stem cell transplantation for haemoglobinopathies," British Journal of Haematology, vol. 141, no. 3, pp. 309-324, 2008.

[73] F. Locatelli, V. Rocha, W. Reed et al., "Related umbilical cord blood transplantation in patients with thalassemia and sickle cell disease," Blood, vol. 101, no. 6, pp. 2137-2143, 2003.

[74] T. V. Adamkiewicz, P. Szabolcs, A. Haight et al., "Unrelated cord blood transplantation in children with sickle cell disease: review of four-center experience," Pediatric Transplantation, vol. 11, no. 6, pp. 641-644, 2007.

[75] J. E. Wagner, J. Rosenthal, R. Sweetman et al., "Successful transplantation of HLA-matched and HLA-mismatched umbilical cord blood from unrelated donors: analysis of engraftment and acute graft- versus-host disease," Blood, vol. 88, no. 3, pp. 795-802, 1996.

[76] J. Kurtzberg, M. Graham, J. Casey, J. Olson, C. E. Stevens, and P. Rubinstein, "The use of umbilical cord blood in mismatched related and unrelated hemopoietic stem cell transplantation," Blood Cells, vol. 20, no. 2-3, pp. 275-284, 1994.

[77] A. A. Maschan, E. V. Skorobogatova, E. V. Samotchatova et al., "A successful cord blood transplant in a child with second accelerated phase chronic myeloid leukemia following lymphoid blast crisis," Bone Marrow Transplantation, vol. 25, no. 2, pp. 213-215, 2000.

[78] A. L. Pecora, P. Stiff, A. Jennis et al., "Prompt and durable engraftment in two older adult patients with high risk chronic myelogenous leukemia (CML) using ex vivo expanded and unmanipulated unrelated umbilical cord blood," Bone Marrow Transplantation, vol. 25, no. 7, pp. 797-799, 2000.

[79] C. Brunstein, D. Setubal, T. DeFor et al., "Umbilical cord blood transplantation for adult patients with chronic myeloid leukemia," Biology of Blood and Marrow Transplantation, vol. 13, no. 2, p. 84, 2007.

[80] G. F. Sanz, S. Saavedra, C. Jiménez et al., "Unrelated donor cord blood transplantation in adults with chronic myelogenous leukemia: results in nine patients from a single institution," Bone Marrow Transplantation, vol. 27, no. 7, pp. 693-701, 2001.

[81] J. Sanz, P. Montesinos, S. Saavedra et al., "Single-unit umbilical cord blood transplantation from unrelated donors in adult patients with chronic myelogenous leukemia," Biology of Blood and Marrow Transplantation, vol. 16, no. 11, pp. 1589-1595, 2010.

[82] A. Sato, J. Ooi, S. Takahashi et al., "Unrelated cord blood transplantation after myeloablative conditioning in adults with advanced myelodysplastic syndromes," Bone Marrow Transplantation, vol. 46, no. 2, pp. 257-261, 2011.

[83] E. D. Warlick, A. Cioc, T. DeFor, M. Dolan, and D. Weisdorf, "Allogeneic stem cell transplantation for adults with myelodysplastic syndromes: importance of pretransplant disease burden," Biology of Blood and Marrow Transplantation, vol. 15, no. 1, pp. 30-38, 2009.

[84] D. A. Wall, S. L. Carter, N. A. Kernan et al., "Busulfan/melphalan/antithymocyte globulin followed by unrelated donor cord blood transplantation for treatment of infant leukemia and leukemia in young children: the Cord Blood Transplantation study (COBLT) experience," Biology of Blood and Marrow Transplantation, vol. 11, no. 8, pp. 637-646, 2005.

[85] J. Kurtzberg, V. K. Prasad, S. L. Carter et al., "Results of the cord blood transplantation study (COBLT): clinical outcomes of unrelated donor umbilical cord blood transplantation in pediatric patients with hematologic malignancies," Blood, vol. 112, no. 10, pp. 4318-4327, 2008.

[86] V. Rocha, M. Labopin, G. Sanz et al., "Transplants of umbilical-cord blood or bone marrow from unrelated donors in adults with acute leukemia," New England Journal of Medicine, vol. 351, no. 22, pp. 2276-2285, 2004.

[87] S. Takahashi, J. Ooi, A. Tomonari et al., "Comparative single-institute analysis of cord blood transplantation from unrelated donors with bone marrow or peripheral blood stemcell transplants from related donors in adult patients with hematologic malignancies after myeloablative conditioning regimen," Blood, vol. 109, no. 3, pp. 1322-1330, 2007.

[88] P. Kumar, T. E. Defor, C. Brunstein et al., "Allogeneic hematopoietic stem cell transplantation in adult acute lymphocytic leukemia: impact of donor source on survival," Biology of Blood and Marrow Transplantation, vol. 14, no. 12, pp. 1394-1400, 2008.

[89] M. B. Tomblyn, M. Arora, K. S. Baker et al., "Myeloablative hematopoietic cell transplantation for acute lymphoblastic leukemia: analysis of graft sources and long-term outcome," Journal of Clinical Oncology, vol. 27, no. 22, pp. 3634-3641, 2009.

[90] Y. Atsuta, R. Suzuki, T. Nagamura-Inoue et al., "Diseasespecific analyses of unrelated cord blood transplantation compared with unrelated bone marrow transplantation in adult patients with acute leukemia," Blood, vol. 113, no. 8, pp. 1631-1638, 2009.

[91] C. G. Brunstein, J. A. Gutman, D. J. Weisdorf et al., "Allogeneic hematopoietic cell transplantation for hematologic malignancy: relative risks and benefits of double umbilical cord blood," Blood, vol. 116, no. 22, pp. 4693-4699, 2010.

[92] J. Ooi, T. Iseki, S. Takahashi et al., "Unrelated cord blood transplantation for adult patients with de novo acute myeloid leukemia," Blood, vol. 103, no. 2, pp. 489-491, 2004.

[93] J. Sanz, M. A. Sanz, S. Saavedra et al., "Cord blood transplantation from unrelated donors in adults with high-risk acute myeloid leukemia," Biology of Blood and Marrow Transplantation, vol. 16, no. 1, pp. 86-94, 2010.

[94] K. K. Ballen, T. R. Spitzer, B. Y. Yeap et al., "Double unrelated reduced-intensity umbilical cord blood transplantation in adults," Biology of Blood and Marrow Transplantation, vol. 13, no. 1, pp. 82-89, 2007.

[95] E. D. Thomas, C. D. Buckner, and J. E. Sanders, "Marrow transplantation for thalassaemia," The Lancet, vol. 2, no. 8292, pp. 227-229, 1982.

[96] T. H. Jaing, I. J. Hung, C. P. Yang, S. H. Chen, C. F. Sun, and R. Chow, "Rapid and complete donor chimerism after unrelated mismatched cord blood transplantation in 5 children with $\beta$-thalassemia major," Biology of Blood and Marrow Transplantation, vol. 11, no. 5, pp. 349-353, 2005. 
[97] T. H. Jaing, C. P. Yang, I. J. Hung, S. H. Chen, C. F. Sun, and R. Chow, "Transplantation of unrelated donor umbilical cord blood utilizing double-unit grafts for five teenagers with transfusion-dependent thalassemia," Bone Marrow Transplantation, vol. 40, no. 4, pp. 307-311, 2007.

[98] T. H. Jaing, P. Tan, J. Rosenthal et al., "166: unrelated cord blood transplantation (UCBT) for transfusion-dependent thalassemia-a retrospective audited analysis of 41 consecutive patients," Biology of Blood and Marrow Transplantation, vol. 13, no. 2, p. 62, 2007. 


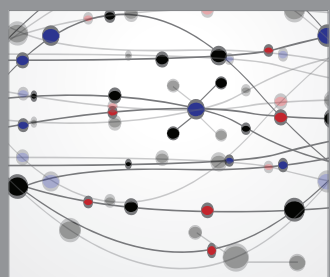

The Scientific World Journal
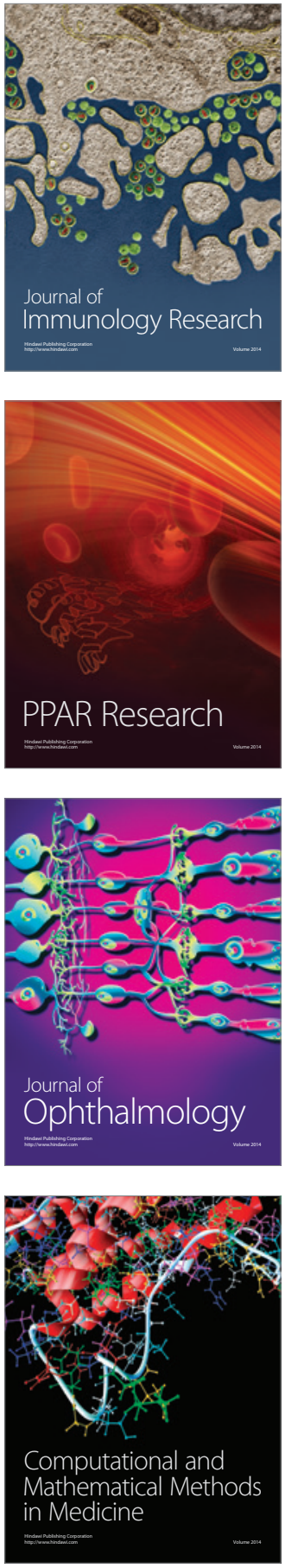

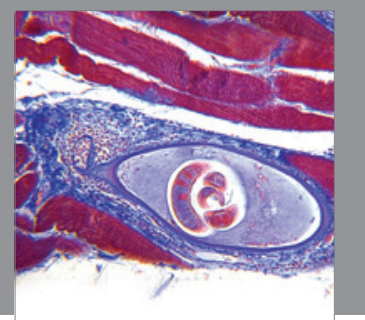

Gastroenterology

Research and Practice
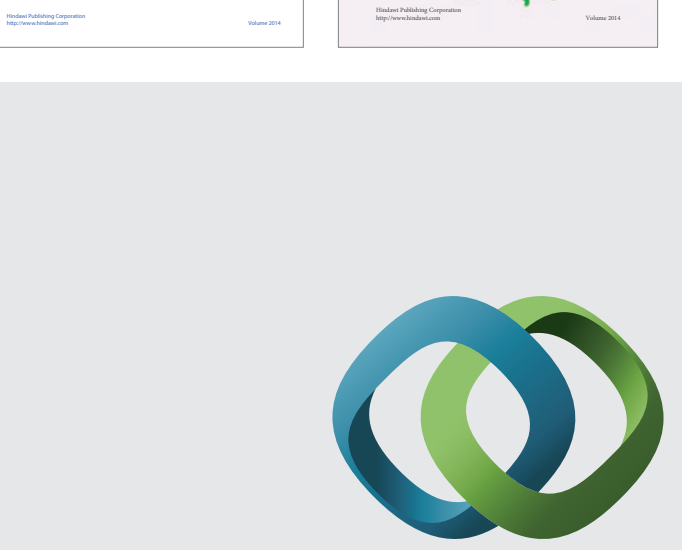

\section{Hindawi}

Submit your manuscripts at

http://www.hindawi.com
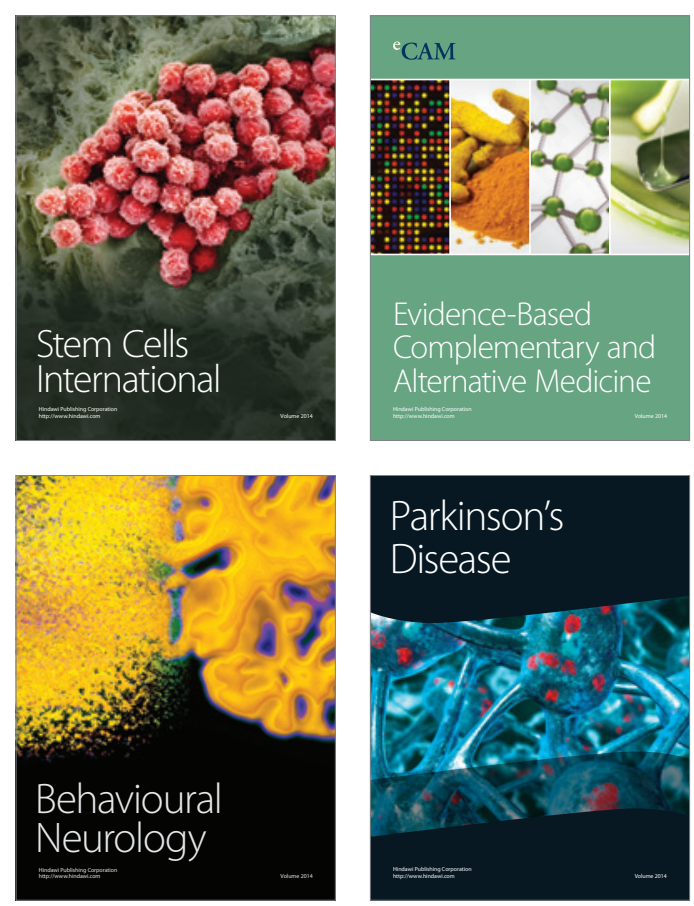

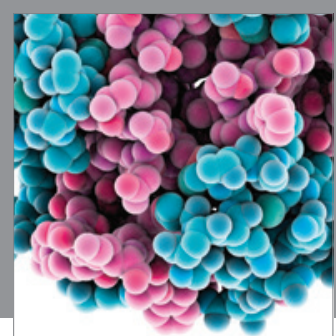

Journal of
Diabetes Research

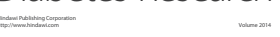

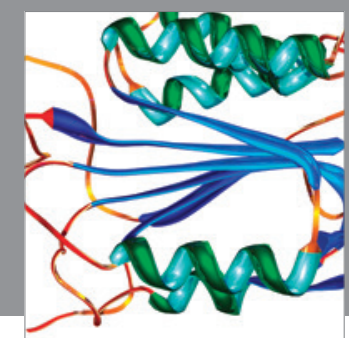

Disease Markers
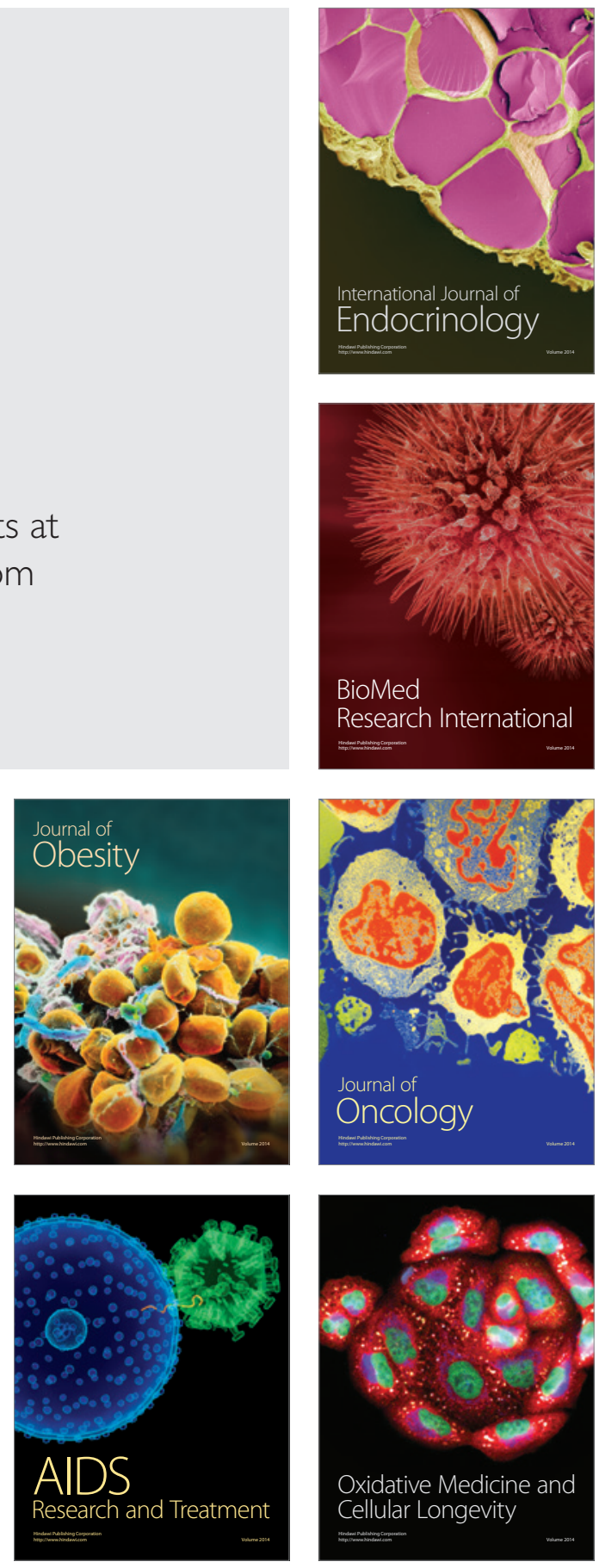